\title{
Influence of different surface treatments of fiberglass posts on the bond strength to dentin
}

\author{
Bruna Cristina do Nascimento Rechia', Ruth Peggy Bravo', Naylin Danyele de Oliveira', Flares Baratto Filho', \\ Carla Castiglia Gonzaga', Carmen L. Mueller Storrer ${ }^{1}$ \\ 'Universidade Positivo - UP, School of Dentistry, Department of Operative Dentistry, Curitiba, PR, Brazil
}

Received for publication: July 20, 2016 Accepted: November 16, 2016

Correspondence to: Carmen L. Mueller Storrer Universidade Positivo - Programa de PósGraduação em Odontologia Rua. Prof. Pedro Viriato Parigot de Souza, 5300. Campo Comprido - Curitiba - PR - BR.

CEP: $81280-330$

Phone: +5541 3317-3454 Fax: $+55413317-3000$

E-mail: Carmen.storrer@gmail.com

\begin{abstract}
Aim: To assess the influence of different fiberglass post surface treatments on the bond strength (BS) to root dentin. Methods: Thirty bovine root canals were endodontically treated and filled with gutta-percha and AH Plus sealer. At $24 \mathrm{~h}$ after the endodontic filling, the post spaces were prepared with Gates-Glidden drills and \#3 drills of the DC White Post system, maintaining a $4 \mathrm{~mm}$ apical seal. The roots were randomly divided into three groups: $S$ (fiberglass posts treated with silane), $\mathrm{SA}$ (fiberglass posts treated with silane and a hydrophobic adhesive system) and SHA (fiberglass posts treated with silane, followed by drying with hot air). The posts were cemented with a selfadhesive cement (RelyX U200). The specimens were stored in distilled water at $37^{\circ} \mathrm{C}$ for $24 \mathrm{~h}$ and subjected to the push-out test $(0.5 \mathrm{~mm} / \mathrm{min})$. Data were statistically analyzed using one-way ANOVA and Tukey's test $(\mathrm{a}=0.05)$ Results: SA and SHA groups showed the highest BS mean values (11.29 and $10.85 \mathrm{MPa}$, respectively), while the $S$ group presented the lowest $B S$ mean value $(7.21 \mathrm{MPa})$. $S$ group was significantly different from SA and SAH groups. Conclusions: The surface treatment of fiberglass posts influenced BS values.
\end{abstract}

Keywords: Dentin-Bonding Agents. Dentin. Denture Retention.

\section{Introduction}

The use of intraradicular posts for improving retention of coronal restoration and enabling coronary reconstruction is guided by the amount of remaining tooth structure after removal of carious tissue and endodontic treatment ${ }^{1-3}$. Posts also help supporting fixed partial dentures ${ }^{4}$, where they dissipate and absorb forces during mastication, in a way that avoids damage to the root and the cementing film.

Fiberglass posts have mechanical, clinical and esthetic advantages, including improved corrosion resistance, biocompatibility, easy removal for endodontic retreatment, rapid insertability and an elastic modulus close to that of dentin; thus, these posts provide a better distribution of occlusal stresses ${ }^{5}$. They can be cemented to the root dentin, which makes the stress on the root more uniform, resulting in fewer root fractures or at least more favorable fractures ${ }^{6}$.

Failure in fiber-reinforced posts results mainly from problems in the luting procedures $^{2,7}$. Cementation of the posts has two functions: retention and stress distribution. Stress distribution is important for preventing fractures due to the potential functional stress transmission of load to the dentin via cement, which becomes a cushion against forces ${ }^{8}$. 
A disadvantage of fiber-reinforced posts is that they cannot achieve intimate adaptation in non-circular, wide or extremely tapered root canals, which may compromise their retention in comparison to customized posts 9 .

In an attempt to provide better retention of fiberglass posts, various surface treatment techniques have been suggested, such as cleaning the post surface with alcohol, conditioning with phosphoric or hydrofluoric acid, sandblasting with aluminum oxide, silicatization, or applying hydrogen peroxide, silane or a hydrophobic adhesive (unfilled resin) on the surface ${ }^{5,10-12}$.

Among the various surface treatments, silanization is one of the most widely used and has the advantage of being a simple procedure that can be performed by the dentist immediately prior to cementing the post, but its effect on the bond strength of the fiberglass post is inconclusive. Some studies have shown that the bond strength between the post and the resin cement may be improved by silanizing the post before cementation ${ }^{13,14}$, while other studies reported that the use of silane alone did not increase bond strength ${ }^{15,16}$.

Silanization may be considered a very sensitive technique. The bond strength of resin cement to the fiberglass posts may be affected by different silane compositions and by the air-drying temperature ${ }^{17}$. Solvent evaporation also plays an important role. Different forms of solvent evaporation or unreacted excess silane may influence the bond strength of the fiberglass post. For feldspathic ceramics and glass ceramics, the use of a hot air jet was reported to help in solvent evaporation and reactions on silanized surfaces, improving bond strength ${ }^{18-21}$. However, there is yet no established protocol for the heat treatment of silane in the literature and results using this approach are controversial ${ }^{22}$.

The aim of this study was to assess the influence of different surface treatments of fiberglass post on the push-out bond strength to root dentin.

\section{Material and methods}

Thirty freshly extracted bovine incisors from healthy cattle were obtained and kept under refrigeration $\left(4^{\circ} \mathrm{C}\right)$ in distilled water changed weekly until the moment of use of the teeth.

The crowns were sectioned perpendicular to the long axis of the tooth, below the level of the cemento-enamel junction, using a diamond disc attached to a precision sectioning saw (Isomet 1000, Buehler, Lake Bluff, IL, USA), under constant refrigeration, in order to create standardized access to the root canal and obtain 14-mm-long root portions.

A single operator performed all root canal fillings. The working length was determined visually at $1 \mathrm{~mm}$ short of the root apex. Rotary instrumentation was performed with ProTaper Universal files (Dentsply Maillefer, Ballaigues, Switzerland) in the SX-S1-S2-F1-F2-F3 sequence, with $2.5 \mathrm{~mL}$ of $2.5 \%$ sodium hypochlorite irrigation during the preparation. The final irrigation was done with $17 \%$ EDTA for $3 \mathrm{~min}$, followed irrigation with $2.5 \mathrm{~mL} 2.5 \%$ sodium hypochlorite and drying with tissue paper points (Dentsply Maillefer). The roots were filled with AH Plus sealer (Denstply DeTreyKonstanz, Germany) and gutta-percha according to the Tagger's hybrid technique.
Twenty-four hours after root canal filling, post spaces were prepared using Gates Glidden drills \#1, 2 and 3, and the \#3 drill of the DC White Post (FGM, Joinville, SC, Brazil) system, maintaining a $4 \mathrm{~mm}$ apical seal. The prepared post spaces were then irrigated with $2.5 \mathrm{~mL} 0.9 \% \mathrm{NaCl}$ solution and dried with paper points (Dentsply Maillefer). After preparation, the roots were randomly divided into the following three groups $(n=10)$, according to the surface treatment of the fiberglass posts (\#3, DC White Post, FGM): Group S (fiberglass posts treated with silane [Ceramic Primer, 3M ESPE, St Paul, MN, USA]), Group SA (fiberglass posts treated with silane and a hydrophobic adhesive system [Adper Scotchbond Multi-Purpose; 3M ESPE]) and Group SHA (fiberglass posts treated with silane, followed by drying with hot air $\left[50^{\circ} \mathrm{C}\right.$ for $\left.60 \mathrm{~s}\right]$ ).

All posts were cleaned with $37 \%$ phosphoric acid for $15 \mathrm{~s}$ (Scotchbond Etchant, 3M ESPE), washed and dried with air jet and then the surface treatments were performed. In $\mathrm{S}$ group, the silane was applied with a microbrush for $60 \mathrm{~s}$; in SA group, after silane treatment, a hydrophobic adhesive layer was also applied with a microbrush, followed by photoactivation for $10 \mathrm{~s}$; in SHA group, silane was applied followed by hot air drying for $60 \mathrm{~s}$ at $50 \mathrm{oC}$. The source of hot air was a hair dryer.

The posts were cemented with a self-adhesive resin cement (RelyX U200; 3M ESPE), with manual pressure, and excess cement was immediately removed. The cement was light-cured for $40 \mathrm{~s}$, with a LED curing unit at $1.100 \mathrm{~mW} / \mathrm{cm}^{2}$ (Poly Wireless, Kavo, Joinville, SC, Brazil). The specimens were stored in distilled water for $24 \mathrm{~h}$ at $37{ }^{\circ} \mathrm{C}$, and were then subjected to the push-out bond strength test.

Two 1-mm thick slices of each root third of the specimens (coronal, medial and apical) were obtained using a diamond disc mounted on a precision sectioning saw (Isomet 1000; Buehler), under constant water cooling. The coronal side of each slice was identified, and each slice was subjected to a push-out bond strength test using a universal testing machine (EMIC DL 2000, São José dos Pinhais, PR, Brazil) at a crosshead speed of $0.5 \mathrm{~mm} /$ min. The load was applied in the apical-coronal direction until the dislodgment of the post. For all tests, the push-out pin on the center of the post surface was carefully placed and different sizes of punch pins were used to match the diameter of the post at the tested different root thirds.

Bond strength (MPa) was obtained by dividing the maximum force in $\mathrm{N}$ by the area of the bonded interface. The area of the truncated cone of each specimen was calculated by the equation:

$$
\mathrm{A}_{\mathrm{L}}=\pi(\mathrm{R}+\mathrm{r}) \sqrt{h^{2}+(R-r)^{2}}
$$

Where AL is the lateral area of a truncated cone, $\pi=3.14$, $\mathrm{R}$ is the coronal post radius, $\mathrm{r}$ is the apical post radius, and $\mathrm{h}$ is the thickness of the root slice. The dimensions of the specimens were obtained with a digital caliper with an accuracy of $0.01 \mathrm{~mm}$.

Fracture surfaces were analyzed using a $57 \times$ stereomicroscope (SZX9, Olympus, Tokyo, Japan) to determine the failure mode. Failures were classified as adhesive (between 
post and cement or between cement and dentin), cohesive (on post or cement) or mixed.

The mean bond strength of each specimen (root) was determined by the bond strength mean value obtained by the six slices, two of each root third. The results of the bond strength values were statistically analyzed using one-way ANOVA and Tukey's test with a significance level of $5 \%$.

\section{Results}

Table 1 shows the mean bond strength values and standard deviations of the evaluated groups as determined by the push-out test (in $\mathrm{MPa}$ ). Statistically significant differences were found in the bond strength values, according to the surface treatments performed on the fiberglass posts $(p=0.038)$. SA and SHA groups showed the highest bond strength values (11.29 and 10.85 $\mathrm{MPa}$, respectively); these values were statistically similar to each other $(p=0.961)$. $S$ group presented the lowest bond strength values (7.21 $\mathrm{MPa})$, and was statistically different from the SA $(\mathrm{p}=0.050)$ and SHA $(\mathrm{p}=0.088)$ groups.

Table 1 - Means and standard deviations of bond strength values as determined using the push-out extrusion test.

\begin{tabular}{lcc}
\hline Groups & Post treatment & Bond strength $(\mathrm{MPa})$ \\
\hline $\mathrm{S}$ & Silane & $7.21 \pm 2.69^{\mathrm{b}}$ \\
$\mathrm{SA}$ & Silane and adhesive & $11.29 \pm 4.27^{\mathrm{a}}$ \\
$\mathrm{SHA}$ & Silane and drying (hot air) & $10.85 \pm 3.35^{\mathrm{a}}$ \\
\hline
\end{tabular}

Values followed by the same superscript are statistically similar $(p>0.05)$.

For all groups, mixed failures were the most frequent failure type (adhesive failures between the dentin and cement and cohesive failures in the cement (Figure 1).

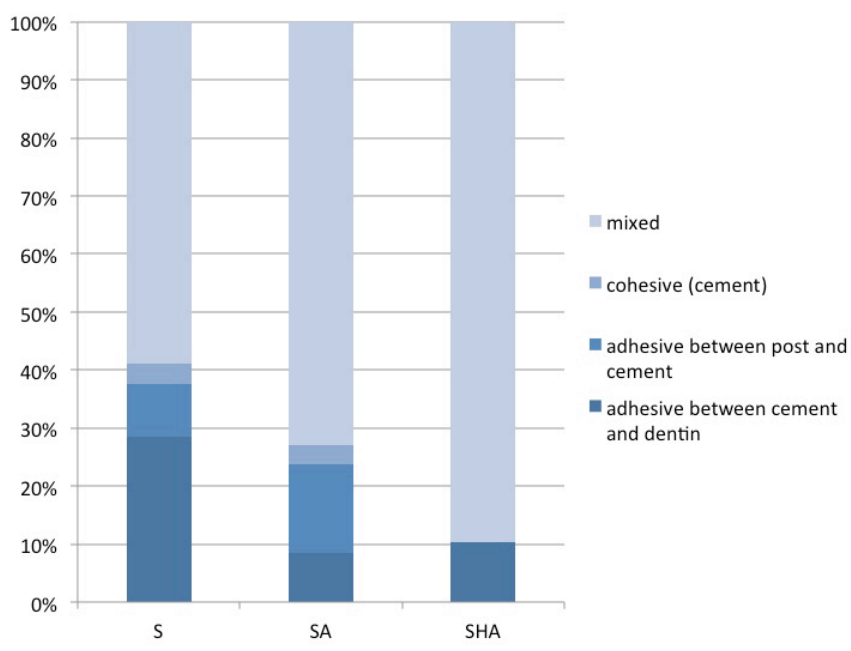

Fig.1. Failure modes observed after push-out bond strength tests for the different groups.

\section{Discussion}

To mimic the restoration of endodontically treated teeth in this study were used fiberglass posts, which possess physical and mechanical properties similar to those of dentin. These posts are more aesthetic, can be rapidly inserted, have lower risk of radicular fractures, do not corrode and may be easily removed, allowing the operator more treatment options with greater efficiency and effectiveness. According to Lamichhane et al. ${ }^{23}$, these posts outperform other materials and systems, and are the best choice for the treatment of teeth with severe damage. Proper bonding of the post to the tooth structure is also essential to a successful outcome of treatment $\mathrm{t}^{2,24-30}$.

The results of the bond strength values found in this study agreed with the results described in the literature, and indicated that the use of hot air after application of silane may improve the strength of bonding of fiberglass posts to dentin ${ }^{31}$.

About the use of silane and adhesive as a post-surface treatment, some studies have shown that there are no statistically significant differences in bond strength values using only silane or silane followed by adhesive, but the bond strength values are lower in the absence of silane ${ }^{32}$. Goracci et al. ${ }^{33}$ evaluated the adhesion between different types of fiber posts and composites after silanization. The bond strength values increased after the application of silane. Silane does not form a suitable bond with an epoxy resin matrix, resulting in poor bonding strength between fiber retainers and resin cement. Thus, before silane application, the surface of the posts should be treated to expose glass fibers.

In this study, the use of an additional adhesive layer after the silane treatment improved the strength of fiberglass post bonding to the root dentin, providing similar bond strength values to those of the group where the silane was hot air dried. Thus, both methods used in the SA and SHA groups may be used to achieve more effective bonding of cemented fiberglass posts.

Another possible explanation for the use of an additional adhesive layer after the silane application is the fact that this material presents mechanical interlocking and chemical reaction with fiberglass posts, improving bond strength. When silane is used alone, it can form a non-homogeneous layer on the post surface. When used in combination with an adhesive layer, both materials can infiltrate the post surface and reinforce the bond with resin cement ${ }^{34}$.

The use of heat-treated silane on the post surfaces is less common than its use to treat feldpsathic or glass ceramics before cementation. ${ }^{35,36}$ The rationale for using hot air jets after silane application relies on the fact that it eliminates alcohol, water and other by-products of the reaction of silane with the substrate ${ }^{37}$ of alcohol evaporation may increase the local density of available connections $^{38}$. In addition, after heat-treating the silane, higher bond strength values may be achieved due to the removal of the upper layers of silane, leaving a more stable silane layer at the bonding interface ${ }^{37}$.

Failure mode analysis showed that, in the three groups, mixed failure was predominant, indicating that there was a good interaction of the resin cement with the post and root dentin after the different surface treatments; thus, the adhesion process was effective ${ }^{31,39-42}$. Previous studies have reported that clinically 
the most frequent failures are adhesive ones, which leads to the displacement of the post ${ }^{2,13,17,43-46}$. As regards post retention in the root dentin, combined failures are considered favorable and even desirable when compared with adhesive failures, since it indicates that the adhesion of the retainer to the dentin was adequate.

It may be concluded that the surface treatment of fiberglass posts influenced bond strength values to dentin. Silane application followed by adhesive treatment and silane followed by hot air drying resulted in higher bond strength values.

\section{References}

1. Cheung W. A Review of the Management of Endodontically Treated Teeth: Post, Core and the Final Restoration. J Am Dent Assoc 2005 May;136(5):611-9.

2. Ferrari M, Mannocci F, Vichi A, Cagidiaco MC, Mjör IA. Bonding to Root Canal: Structural Characteristics of the Substrate. Am J Dent. 2000 Oct;13(5):255-60.

3. Mosharraf R, Ranjbarian P. Effects of Post Surface Conditioning Before Silanization on Bond Strength between Fiber Post and Resin Cement. J Adv Prosthodont 2013 May;5(2):126-32. doi: 10.4047/jap.2013.5.2.126.

4. Sheets CE. Dowel and Core Foundations. J Prosthet Dent 1972 Sep;3(9):45-7.

5. Liu C, Liu H, Qian YT, Zhu S, Zhao SQ. The Influence of Four Dual-Cure Resin Cements and Surface Treatment Selection to Bond Strength of Fiber Post. Int J Oral Sci. 2014 Mar;6(1):56-60. doi: 10.1038/ ijos.2013.83.

6. Costa RG, De Morais EC, Campos EA, Michel MD, Gonzaga CC, Correr GM. Customized Fiber Glass Posts. Fatigue and Fracture Resistance. Am J Dent. 2012 Feb;25(1):35-8.

7. Ferrari M, Vichi A, Fadda GM, Cagidiaco MC, Tay FR, Breschi L, et al. A Randomized Controlled Trial of Endodontically Treated and Restored Premolars. J Dent Res. 2012 Jul;91(7 Suppl):72S-78S.

8. Leary JM, Jensen ME, Sheth JJ. Load Transfer of Posts and Cores to Roots through Cements. J Prosthet Dent 1989 Sep;62(3):298-302.

9. Lee JH, Sohn DS, Lee CHL. Fabricating a Fiber-Reinforced Post and Zircônia Core with CAD/CAM Technology. J Prosthet Dent 2014 Sep;112(3):683-5. doi: 10.1016/j.prosdent.2014.01.015.

10. Menezes MS, Queiroz EC, Soares PV, Faria-e-Silva AL, Soares CJ, Martins LR. Fiber post etching with hydrogen peroxide: effect of concentration and application time.J Endod. 2011 Mar;37(3):398-402.

11. Güler AU, Kurt M, Duran I, Uludamar A, Inan O. Effects of Different Acids and Etching Times on the Bond Strength of Glass Fiber-Reinforced Composite Root Canal Posts to Composite Core Material. Quintessence Int. 2012 Jan;43(1):e1-8.

12. Asakawa $\mathrm{Y}$, Takahashi $\mathrm{H}$, Kobayashi M, Iwasaki N. Effect of Components and Surface Treatments of Fiber-Reinforced Composite Posts on Bond Strength to Composite Resin. J Mech Behav Biomed Mater. 2013 Oct;26:23-33. doi: 10.1016/j.jmbbm.2013.05.022.

13. Goracci C, Tavares AU, Fabianelli A, Monticelli F, Rafaelli O, Cardoso PC. The Adhesion between Fiber Posts and Root Canal Walls: Comparison between Microtensile and Push-Out Bond Strength Measurements. Eur J Oral Sci 2004 Aug;112(4):353-61.

14. Monticelli F, Toledano M, Tay FR, Cury AH, Goracci C, Ferrari M. Post-Surface Conditioning Improves Interfacial Adhesion in Post/Core Restorations. Dent Mater. 2006 Jul;22(7):602-9.

15. Perdigão J, Gomes G, Lee IK. The Effect of Silane on the Bond Strengths of Fiber Posts. Dent Mater. 2006 Aug;22(8):752-8.

16. Wrbas KT, Altenburger MJ, Schirrmeister JF, Bitter K, Kielbassa AM. Effect of Adhesive Resin Cements and Post Surface Silanization on the Bond Strengths of Adhesively Inserted Fiber Posts. J Endod. 2007
Jul;33(7):840-3.

17. Monticelli F, Toledano M, Osorio R, Ferrari M. Effect of Temperature on the Silane Coupling Agents when Bonding Core Resin to Quartz Fiber Posts. Dent Mater. 2006 Nov;22(11):1024-8.

18. Barghi N, Berry T, Chung K. Effects of Timing and Heat Treatment of Silanated Porcelain on the Bond Strength. J Oral Rehabil. 2000 May;27(5):407-12.

19. Shen C, Oh WS, Williams JR. Effect of Post-Silanization Drying on the Bond Strength of Composite to Ceramic. J Prosthet Dent. 2004 May;91(5):453-8

20. Fabianelli A, Pollington S, Papacchini F, Goracci C, Cantoro A, Ferrari $M$, et al. The Effect of Different Surface Treatments on Bond Strength between Leucite Reinforced Feldspathic Ceramic and Composite Resin. J Dent. 2010 Jan;38(1):39-43. doi: 10.1016/j.jdent.2009.08.010.

21. Corazza PH, Cavalcanti SC, Queiroz JR, Bottino MA, Valandro LF. Effect of Post-Silanization Heat Treatments of Silanized Feldspathic Ceramic on Adhesion to Resin Cement. J Adhes Dent. 2013 Oct;15(5):473-9. doi: 10.3290/j.jad.a29592.

22. Carvalho RF, Martins ME, de Queiroz JR, Leite FP, Ozcan M. Influence of Silane Heat Treatment on Bond Strength of Resin Cement to a Feldspathic Ceramic. Dent Mater J. 2011;30(3):392-7.

23. Lamichhane A, Xu C, Zhang FQ. Dental Fiber-Post Resin Base Material: a Review. J Adv Prosthodont 2014 Feb;6(1):60-5. doi: 10.4047/ jap.2014.6.1.60.

24. Scotti R, Ferrari M. Pinos de Fibra Considerações Teóricas e Aplicações Clínicas. São Paulo: Artes Médicas; 2003

25. Bouillaguet S, Troesch S, Wataha JC, Krejci I, Meyer JM, Pashley DH. Microtensile Bond Strength between Adhesive Cements and Root Canal Dentin. Dent Mater 2003 May;19(3):199-205.

26. Grandini S, Goracci C, Tay FR, Grandini R, Ferrari M. Clinical Evaluation of the Use of Fiber Posts and Direct Resin Restorations for Endodontically Treated teeth. Int J Prosthodont 2005 SepOct:18(5):399-404.

27. Schmage P, Cakir FY, Nergiz I, Pfeiffer P. Effect of Surface Conditioning on the Retentive Bond Strengths of Fiber-Reinforced Composite Posts. I Prosthet Dent 2009 Dec;102(6):368-77. doi: 10.1016/S00223913(09)60196-7.

28. Da Rosa RA, Bergoli CD, Kaizer OB, Valandro LF. Influence of Cement Thickness and Mechanical Cycling on the Push-out Bond Strength between Posts and Root Dentin. Gen Dent. 2011 Jul-Aug;59(4):e156-61.

29. Egilmez F, Ergun G, Cekic-Nagas I, Vallittu PK, Lassila LV. Influence of Cement Thickness on the Bond Strength of Tooth-Colored Posts to Root Dentin after Thermal Cycling. Acta Odontol Scand. 2013 Jan;71(1):17582. doi: 10.3109/00016357.2011.654257.

30. Gomes GM, Rezende EC, Gomes OM, Gomes JC, Loguercio AD, Reis A. Influence of the Resin Cement Thickness on Bond Strength and Gap Formation of Fiber Posts Bonded to Root Dentin. J Adhes Dent. 2014 Feb;16(1):71-8. doi: 10.3290/j.jad.a30878.

31. Samimi P, Mortazavi V, Salamat F. Effects of Heat Treating Silane and Different Etching Techniques on Glass Fiber Post Push-Out Bond Strength. Oper Dent. 2014 Sep-Oct;39(5):E217-24. doi: 10.2341/11486-L.

32. Leme AA, Pinho AL, de Gonçalves L, Correr-Sobrinho L, Sinhoreti MA. Effects of Silane Application on Luting Fiber Posts using Self-Adhesive Resin Cement. J Adhes Dent. 2013 Jun;15(3):269-74. doi: 10.3290/j. jad.a28881.

33. Goracci C, Raffaelli O, Monticelli F, Balleri B, Bertelli E, Ferrari M. The Adhesion between Prefabricated FRC Posts and Composite Resin Cores: Microtensile Bond Strength with and without Post-Silanization. Dent Mater. 2005 May;21(5):437-44.

34. Cecchin D, Farina AP, Vitti RP, Moraes RR, Bacchi A, Spazzin AO. Acid Etching and Surface Coating of Glass-Fiber Posts: Bond Strength and Interface Analysis. Braz Dent J. 2016 Mar-Apr;27(2):228-233. 
35. Baratto SS, Spina DR, Gonzaga CC, Cunha LF, Furuse AY, Baratto Filho F, Correr GM Silanated Surface Treatment: Effects on the Bond Strength to Lithium Disilicate Glass-Ceramic. Braz Dent J. 2015 Oct;26(5):474-7.

36. Cotes C, de Carvalho RF, Kimpara ET, Leite FP, Ozcan M. Can heat treatment procedures of pre-hydrolyzed silane replace hydrofluoric acid in the adhesion of resin cement to feldspathic ceramic? J Adhes Dent. 2013 Dec;15(6):569-74.

37. Hooshmand T, van Noort R, Keshvad A. Bond durability of the resinbonded and silane treated ceramic surface. Dent Mater 2002;18:179-88.

38. Shen C, Oh WS, Williams JR. Effect of post-silanization drying on the bond strength of composite to ceramic. J Prosthet Dent 2004;91:453458.

39. Martinho FC, Carvalho CAT, Oliveira LD, Lacerda AJF, Xavier ACC, Augusto MG, et al. Comparison of Different Dentin Pretreatment Protocols on the Bond Strength of Glass Fiber Post Using Self-etching Adhesive. JOE 2015 Jan;41(1):83-7. doi: 10.1016/j.joen.2014.07.018.

40. Kim YK, Son JS, Kim KH, Kwon TY. A Simple 2-step Silane Treatment for Improved Bonding Durability of Resin Cement to Quartz Fiber Post. JOE 2013 Oct;39(10):1287-90. doi: 10.1016/j.joen.2013.06.010.

41. Rosatto CMP, Roscoe AG, Novais VR, De Souza Menezes M, Soares CJ.
Effect of Silane Type and Air-Drying Temperature on Bonding Fiber Post to Composite Core and Resin Cement. Braz Dent J 2014;25(3):217-24.

42. Zaghloul H, Elkassas DW, Haridy MF. Effect of Incorporation of Silane in the Bonding Agent on the Repair Potential of Machinable Esthetic Blocks. Eur J Dent 2014 Jan;8(1):44-52. doi: 10.4103/13057456.126240

43. Elsaka SE. Influence of chemical surface treatments on adhesion of fiber posts to composite resin core materials. Dental Materials 2013 May;29(5):550-8. doi: 10.1016/j.dental.2013.03.004.

44. Chen Q, Cai Q, Li Y, Wei XY, Huang Z, Wang XZ. Effect on Push-out Bond Strength of Glass-fiber Posts Functionalized with Polydopamine Using Different Adhesives. J Adhes Dent 2014 Apr;16(2):177-84. doi: 10.3290/j.jad.a31810.

45. Majeti C, Veeramachaneni C, Morisetty PK, Rao SA, Tummala M. A Simplified Etching Technique to Improve the Adhesion of Fiber Post. J Adv Prosthodont 2014 Aug;6(4):295-301. doi: 10.4047/jap.2014.6.4.295.

46. Yilmaz SK, Cengiz E, Ozan O, Ramoglu S, Yilmaz HG. The Effect of Er,Cr:YSGG Laser Application on the Micropush-Out Bond Strength of Fiber Posts to Resin Core Material. Photomed Laser Surg 2014 Oct;32(10):574-81. doi: 10.1089/pho.2014.3780. 